\title{
Women's and Midwives' Perspectives on the Design of a Text Messaging Support for Maternal Obesity Services: An Exploratory Study
}

\author{
H. Soltani, ${ }^{1}$ P. J. Furness, ${ }^{2}$ M. A. Arden, ${ }^{2}$ K. McSeveny, ${ }^{3}$ C. Garland, ${ }^{4}$ \\ H. Sustar, ${ }^{5}$ and A. Dearden ${ }^{3}$ \\ ${ }^{1}$ Health and Social Care Research Centre, Sheffield Hallam University, 32 Collegiate Crescent, Sheffield S10 2BP, UK \\ ${ }^{2}$ Department of Psychology, Sociology \& Politics, Sheffield Hallam University, Collegiate Crescent, Sheffield S10 2BP, UK \\ ${ }^{3}$ Communication and Computing Research Centre, Sheffield Hallam University, Cantor Building, 153 Arundel Street, Sheffield S1 2NU, \\ $U K$ \\ ${ }^{4}$ Maternal Obesity Clinic, Doncaster and Bassetlaw Hospitals NHS Foundation Trust, Armthorpe Road, Doncaster, DN2 5LT, UK \\ ${ }^{5}$ Sheffield Hallam University, Cantor Building, 153 Arundel Street, Sheffield S1 2NU, UK
}

Correspondence should be addressed to H. Soltani, h.soltani@shu.ac.uk

Received 9 March 2012; Revised 21 May 2012; Accepted 27 May 2012

Academic Editor: Aron Weller

Copyright ( $) 2012$ H. Soltani et al. This is an open access article distributed under the Creative Commons Attribution License, which permits unrestricted use, distribution, and reproduction in any medium, provided the original work is properly cited.

This study was aimed to explore women's and midwives' views on the use of mobile technology in supporting obese pregnant women with healthy lifestyle choices. A purposive sample of 14 women and midwives participated in four focus groups in Doncaster, UK. A content analysis of the transcripts from the first focus group led to the emergence of three main constructs with associated subcategories including Benefits ("modernising," "motivating," "reminding," and "reducing" the sense of isolation), Risks and Limitations (possibility of "being offensive," "creating pressure or guilt," and "being influenced by mood"), and Service Delivery (making it "available to all pregnant women," giving attention to the "message tone" and development of "message content"). They also suggested the use of other modalities such as web-based services for weight management during pregnancy. Based on the above results a text messaging service was developed and presented to the 2 nd focus group participants who confirmed the positive views from the first focus group on the use of the text messaging as being supportive and informative. The participants also welcomed "women's engagement and choice" in deciding the content, timing and frequency of messages. The results informed the development of a text messaging service to support maternal obesity management. The implementation and acceptability of this service requires further investigation.

\section{Introduction}

Obesity (body mass index (BMI) $\geq 30 \mathrm{~kg} / \mathrm{m}^{2}$ ) is a major worldwide public health challenge [1]. Twenty-three percent of the UK population are obese, and predictions warn prevalence will rise to over $50 \%$ by 2050 [2]. Around $20 \%$ of pregnant women in the UK are obese [3]. According to the Confidential Enquiry into Maternal and Child Health [4], obesity and overweight are directly or indirectly associated with over half of the total maternal deaths. Prepregnancy obesity and excessive weight gain during pregnancy are associated with adverse outcomes during pregnancy and birth [5-8], increased postpartum fat retention [9], and obesity in the offspring [10]. Obesity in pregnancy also has considerable cost implications for health service provision $[5,11]$. Above all, a recent large scale observational cohort study of Swedish women [12] showed evidence of benefit with no adverse outcomes for obese pregnant women with weight gain within the 2009 Institute of Medicine (IOM) guidelines [13].

Although behavioural and pharmacological interventions for obesity in the general population are well explored, there is scope for more research into the efficacy of weight control interventions in pregnancy, since existing published 
evidence is inconclusive $[14,15]$. The lack of clear guidance for the management of maternal obesity is confirmed by the National Institute for Health and Clinical Excellence (NICE) report (2010) in which further UK-based research in this area is recommended [16]. Sarwer and colleagues suggest future research should focus upon novel, creative modes of intervention using, for example, telephone and internetbased programs [17]. Heron and Smyth [18] comment that mobile technology is portable, instantly accessible, private, and can be individually tailored. This allows health professionals to extend the reach of traditional face-to-face interventions and offer the client additional support at times and in locations which are convenient for them to act on that support and advice. These interventions may be more acceptable to groups such as children and young adults, who are more familiar with mobile technology and there can be considerable up-front set-up costs; however, overall treatment costs may be reduced [18].

Mobile phones are now the most widely used communication technology in the world and provide unprecedented opportunities for health promotion. In the UK, for example, there are 131 mobile phone subscriptions per 100 of the population [19]. WHO [19] reports that mobile phones have been used for consultation purposes, to promote communication between healthcare users and providers, to survey or provide information to users and remind them of appointments, and stresses the importance of evaluative research in this area. Heron and Smyth's review [18] indicates that mobile technology-based interventions in general can be effective in addressing a range of health behaviours, including weight loss, diet, and exercise [20-23]. RCTs have demonstrated effectiveness of text messaging interventions to raise awareness and change behaviour in sexual health [24-26] and self-management of diabetes [27]. In obesity management, Haapala et al.'s 12-month RCT [28] and Joo and Kim's 12-week trial [22] reported significant weight loss in text messaging intervention recipients, and Hurling and colleagues [29] reported significant weight loss and increased physical activity from their internet and (short messaging service) SMS-based intervention.

Systematic reviews report relatively consistent success among SMS-based trials in achieving significant weight loss $[18,30-32]$, as well as self-management of diabetes [33], although findings relating to other healthy behaviours, such as smoking cessation and physical activity, vary ([34] comp. $[32,35])$. The study by Stewart Agras et al. [20] is one of the few studies to thoroughly cost analyse their interventions and found that, per kilogram of weight lost, the mobile technology-support group treatment was half the cost of the other treatments, and therefore, most cost effective. The combined evidence suggests that mobile phone messages can be effective in the general population in achieving change in health behaviours without incurring prohibitive extra cost to the service provider. To the authors' knowledge, however, there is no evidence to date in the UK regarding the use of SMS messages to support healthy lifestyles in the obese pregnant woman.

The effectiveness of interventions also depends upon their feasibility in practice and acceptability to service users and providers. Heron and Smyth [18] comment that more should be done to evaluate these aspects of mobile technology interventions; however, the few reviewed studies which reported participant satisfaction levels found favourable reactions and satisfaction with the interventions. Heron and Smyth [18] argue that acceptability and feasibility are facilitated by involvement of service users and providers in intervention design and in gathering participant feedback in pilot tests prior to implementing controlled trials. They also note that service provider barriers to successful implementation should be investigated, such as lack of technological knowledge, cost and time investment, and scepticism. Similarly, Oteng-Ntim et al. [36], who explored service providers' views regarding maternal obesity interventions, recommended that both service providers' and service users' perspectives should be sought when developing new services to ensure they are not only theoretically effective but also feasible and acceptable to those who will utilise them.

This paper reports the development of a mobile technology intervention, based upon SMS messages, to support obese pregnant women with weight management. If local trials of the developed service are successful, it is intended that the service will be extended to other areas for a larger evaluation. The study had three aims and stages: firstly, to gather women's and midwives' opinions regarding using mobile technology, and in particular SMS text messages, to support obese pregnant women in managing their weight; secondly, to develop an SMS-based intervention based upon first stage data and theoretical perspectives; thirdly, to gather opinions from women and midwives regarding the developed service. (Women and midwives were also asked about their experiences of obesity and weight management/caring for obese pregnant women, and their perceptions of existing services, but these findings are reported elsewhere [37]).

\section{Materials and Methods}

This qualitative study used focus group methodology to gather data on two occasions from obese pregnant women (BMI of $30 \mathrm{~kg} / \mathrm{m}^{2}$ or above) and midwives delivering maternity services in Doncaster in 2011, once before and once after development of the proposed SMS-based service to support pregnant women with weight management.

\subsection{Participants and Recruitment. Following university, NHS} (South Yorkshire Research Ethics Committee), and local ethical approvals, maternity service users (BMI $\geq 30 \mathrm{~kg} / \mathrm{m}^{2}$ ) in Doncaster, UK, and midwives delivering maternity services to women in this area were approached to participate. Doncaster is a town in the north of England with high levels (relative to the national average) of socioeconomic deprivation [38]. Deprivation is linked to maternal obesity [11], and in 2009, the prevalence of obesity at conception among Doncaster women was $20 \%$.

Purposive sampling was employed to ensure inclusion of obese midwifery service users and health care providers with experience of maternal obesity from community and hospital 
settings. Local midwives provided eligible women $(n=60)$ with a letter and information sheet describing the project with reply slips to return to the researcher if they wished to participate. All midwives $(n=45)$ were informed about the study via email.

The total number of participants in the study was 14 , participating in 4 focus groups. Six women and 7 midwives initially volunteered and took part in the first set of two focus groups. Five of these women were also available and participated in the second set of two focus groups; three of the midwives agreed to participate in the second stage and they were joined by one additional midwife who had not participated in the first stage. The sample size in this study was guided by the practicality and data saturation to ensure rich and in-depth information are provided [39]. Demographic data were not collected specifically; however, it was evident from observation and through discussion that the women were all white, which is broadly in keeping with the local area, aged 18 to 40, and had experienced between 1 and 4 pregnancies. Midwives were all white, female, from both community and hospital settings, and varied from a few years' to decades of midwifery experience.

2.2. Data Collection. Semistructured focus groups were used to collect data, whose aim was to facilitate interaction between participants in a permissive, comfortable environment [40]. Participant numbers (1st stage: $n=6$ women; 7 midwives; 2 nd stage: $n=5$ women; 4 midwives) were considered optimal in generating a range of ideas and maximising involvement in discussion of this novel subject. In order to eliminate the possible detrimental impact of hierarchy, conflict of opinion, discomfort and inhibition upon participants' contributions to the discussion, and the resulting dataset, women and midwives participated in separate focus groups, each lasting for around 1 hour. The first two focus groups were held on separate dates in a local children's centre, a familiar environment chosen to provide a welcoming, neutral context for discussions. Several months later, following service design and a demonstration to all participants of the developed service, the second focus groups were run simultaneously (but separately) in two adjacent hospital seminar rooms.

In the first focus groups, women and midwives were asked for their opinions about the idea of using text messages to support obese pregnant women in managing their weight, thoughts about message content and delivery, and ideas for other forms of supportive mobile technology. In the second, the participants were asked for their opinions about the service which had been developed and ideas for further development and improvements. In each case, two experienced facilitators guided the conversation but were otherwise minimally involved to ensure that participants' views were predominant [41]. Focus group discussions were audio-recorded with participants' consent.

2.3. Data Analysis. For each stage of data collection, focus group data were transcribed and anonymised immediately after the focus groups, and all participants were allocated a pseudonym. Transcriptions were loaded into NVivo 8, a software package which assists in qualitative data analysis by facilitating storage, organization, and retrieval processes. Data analysis was an inductive process of qualitative content analysis [42], which comprised careful reading and coding of all data, and generation of categories of related data. For the purpose of interrater reliability, initial analysis was conducted independently by two researchers, who agreed categories. These were verified by a third researcher and then discussed and approved by the team.

2.4. Development of the SMS Service. A multidisciplinary team of academics from the fields of midwifery, health psychology, design and technology, and sociolinguistic science and dietitians as well as service user representatives collaborated to create an SMS service to support pregnant women with weight management. The service included a series of text messages, a platform for allowing midwives and clients to discuss and select appropriate messages and schedules for their delivery and a mechanism for distribution of the messages. The service development was based upon combined experience and expertise of the team, the focus group data from phase 1, and evidence-based techniques for healthy eating and physical activity behaviour change [43]. The service is described in more detail in Section 3.

\section{Results}

3.1. Focus Group One. Data categories emerging from the first focus groups, whose aim was to explore perceptions of the potential for text messages to support weight management in obese pregnant women' comprised "Benefits," "Risks and Limitations," and "Service Delivery." These and their subcategories are described here and presented with illustrative focus group extracts in Table 1. Midwife quotations are identified by the letters "MW" after the participant's pseudonym.

3.2. Benefits. Both women and midwives were positive about the idea of mobile phone messages to support pregnant women with weight management, highlighting benefits as "modernising," "motivating," "reminding" and "reducing sense of isolation." Women in particular believed the text message intervention would help modernise maternity services, which were "still a bit old-fashioned" (Alice) and improve cost effectiveness. They also felt that the regular contact and support through SMS messages would help motivate and remind women to maintain healthy lifestyles and reduce their sense of isolation. In keeping with Evenson et al. [44], we found that lack of motivation and social support were considered by the women and midwives as two of the main barriers to healthy diet and physical activity in pregnancy [37]. The notion that SMS messages could help motivate and remind women about their goals and increase their sense of being supported suggests they could be effective in reducing those barriers and increasing the likelihood of healthy lifestyles.

3.3. Risks and Limitations. Participants (primarily midwives) perceived that SMS messages had some inherent risks and 
TABLE 1: Results from the first focus group of women and midwives on the use of text messaging services in support of maternal obesity management.

\begin{tabular}{|c|c|c|}
\hline Categories & Subcategories & Data extracts \\
\hline \multirow{4}{*}{ Benefits } & Modernising & $\begin{array}{l}\text { [we are] comfortable with using online technology to find things our } \\
\text { and get information ... [it's] probably is the best way to go, isn't } \\
\text { it, because it's cheaper than-well I'm assuming it's cheaper than- } \\
\text { having more face to face options' (Alice) }\end{array}$ \\
\hline & Motivating & $\begin{array}{l}\text { All you need sometimes is just that one person to say, "come on, do it," } \\
\text { and it just helps you, doesn't it? (Rachel) }\end{array}$ \\
\hline & Reminding & $\begin{array}{l}\text { In those } 4 \text { weeks [between appointments] it would have been nice to } \\
\text { get the odd text message, just to make sure you are still on the right } \\
\text { track. That text message might make you think, "oh, I won't have that } \\
\text { chocolate bar now, I'll have something else" (Sally) }\end{array}$ \\
\hline & Reducing isolation & $\begin{array}{l}\text { I think the fact somebody, just somebody is communicating with } \\
\text { you, even though it's a text message, throughout your pregnancy, you } \\
\text { wouldn't feel as lonely and you'd think, y'know, "there is somebody } \\
\text { there" (Jenny) }\end{array}$ \\
\hline \multirow{4}{*}{ Risk and limitations } & Potential for offence, pressure, or guilt & $\begin{array}{l}\text { It's a fine line between encouraging people and putting too much } \\
\text { pressure on people, and there are some people who would possibly } \\
\text { take it too far to the extreme, and maybe under-eat or see it as too } \\
\text { much pressure. I don't mean to be negative but I just think that, not } \\
\text { everybody, but some people, might find it too much pressure (Alice) }\end{array}$ \\
\hline & \multirow[t]{3}{*}{ Impact limited by mood or motivation } & $\begin{array}{l}\text { Kathy (MW) [when] I'm feeling more motivated and focused I } \\
\text { wouldn't mind [a message]. So that's quite important isn't it, when } \\
\text { we all feel that... }\end{array}$ \\
\hline & & Anna (MW): It's the frame of mind \\
\hline & & $\begin{array}{l}\text { Kathy (MW): In that frame of mind, that motivational message is } \\
\text { great. But on a fat day, that motivational message might make you } \\
\text { feel like "oh I can't be bothered today" }\end{array}$ \\
\hline \multirow{6}{*}{ Service delivery } & Available to all & $\begin{array}{l}\text { We've got to tell all women ... not just focusing on women who've got } \\
\text { high BMIs, it's focusing on every single woman and advising about } \\
\text { pregnancy (Jane, MW) }\end{array}$ \\
\hline & Positive and sensitive message tone & $\begin{array}{l}\text { You'd have to make sure you got the tone of the message really right, } \\
\text { maybe ... put something really positive in like "you're doing a really } \\
\text { good job so far," or something like that, rather than just "Go for a } \\
\text { walk!" or "Don't eat that doughnut!" (group laughter) (Alice) }\end{array}$ \\
\hline & \multirow{3}{*}{$\begin{array}{l}\text { Personalised and informative message } \\
\text { content }\end{array}$} & $\begin{array}{l}\text { If you got a text message maybe that morning saying "so and so class } \\
\text { is on today," or tonight, or tomorrow, and then you're more likely to } \\
\text { remember to go and to be motivated cause you can like psych yourself } \\
\text { up for it (Sally) }\end{array}$ \\
\hline & & $\begin{array}{l}\text { Jenny: What about texting you a quick recipe for your tea or something } \\
\text { like that? }\end{array}$ \\
\hline & & $\begin{array}{l}\text { Lucy: Yeah, like what to eat or don't eat as snacks tonight .... } \\
\text { Jenny: Change your crisps for an apple type of thing (laughter) }\end{array}$ \\
\hline & $\begin{array}{l}\text { Other mobile technologies (e.g., web- } \\
\text { based networking) }\end{array}$ & $\begin{array}{l}\text { A chat room web page just for Doncaster people, so for people using the } \\
\text { internet like me and Lucy, you can talk to other mums in Doncaster, } \\
\text { arrange a night out for tea, or a night out going doing a walk round the } \\
\text { lakeside or something, cause you, cause you're all local you can all talk } \\
\text { to each other (Rachel) }\end{array}$ \\
\hline
\end{tabular}

limitations, including "Potential to create offence, pressure or guilt" and "Impact limited by mood or motivation." Participants were concerned that messages might be perceived as intrusive or pressurising and some midwives were concerned that messages could be seen as insensitive by women having difficulties with their pregnancy. Participants also believed that the effectiveness of messages might be limited by recipients' mood or levels of motivation. Motivation was 
a key issue raised by both sets of participants [37], and midwives perceived that an SMS-based service would be most successful with motivated clients.

3.4. Service Delivery. Given its potential benefits and risks, women and midwives had strong opinions about the design of the SMS service and made a number of suggestions about "Availability," "Message Tone," Message Content' and "Other Forms of Mobile Technology." Participants believed there were clear benefits for obese pregnant women in the proposed SMS service; however, they felt that the service should be optional and available to all women, regardless of BMI, and to women both during and after their pregnancy. Participants agreed that messages should be positive and sensitive, to maximise motivational potential and avoid "making people feel guilty" (Jane, MW). Midwives were mindful of creating offence through incautious use of language or issuing direct orders to women about their diet or exercise. Both groups felt that health promotion messages focused on the risks and complications of obesity and unhealthy lifestyles were inappropriate for text messages. These, it was considered, were better delivered traditionally, face-to-face, so that midwives could ensure women were fully informed and supported.

The women had many ideas for the types of messages they would find useful in helping them manage their weight. For maximum effectiveness they believed messages should be personalised (focused upon individual goals and lifestyle) and could include contextually relevant information such as times of exercise classes, exercise suggestions, healthy eating ideas, recipes, and baby's progress. They also considered that text messages could be used to help women to get together for social contact and exercise (such as group walks). They perceived that spending time with other women in similar circumstances would have supported them in their efforts to be healthy and avoid gaining excessive weight in pregnancy [37].

3.5. Other Forms of Mobile Technology. Women mentioned other possibilities for supportive mobile technology interventions for obese pregnant women, including online midwives and an internet chat room, the main benefits of which were extra opportunities to get support from midwives and meet other local women. The midwives, not surprisingly, were a little more circumspect about these ideas. They were concerned about time constraints, confidentiality, and the risks of giving advice in the open-access arena of an online chat room, given that "what's right for one woman might not necessarily be right for somebody els" (Jane, MW).

3.6. Developing the SMS Service. Service development included creating a flexible, web-based platform for automated delivery of messages to women based upon their needs, habits, and preferences. The platform was designed to be usable within the constraints of the existing local midwifedelivered services offered to obese pregnant women. A usercentred and participatory design approach was applied [45], focusing on the midwife as the primary user of the web-based interface to the system. The midwife can log into the system and use it through any standard web browser.

A set of messages was developed, based upon focus group results and informed by established theoretical models of behaviour change from the field of health psychology. Experts (such as dietitians and sociolinguists) and a service user separate from the study participants were also involved in message development. Message suggestions were reviewed and amended during team meetings, resulting in a final set of 96 messages which were approved by all involved. These included generic "starter" messages to familiarise the woman with receiving messages and to create the basis for later discussion and choice of personalised messages. Approved messages were collated and presented in a booklet with separate sections for generic and goal-related messages according to related dietary and physical activity objectives. The latter were divided to 4 categories of motivation, specific planning, overcoming barriers, and prompting selfmonitoring. Examples of the types and content of generic and goal-related messages are provided in Table 2.

Women who opt into the service will be introduced to the service and given the opportunity at an initial consultation with the obesity specialist midwife (14-16 gestational weeks) to select some generic messages. This will enable them to get used to the system and explore their feelings about the number and types of messages. At the second consultation (2 weeks later), the women will be asked to set specific goals for both diet and exercise, to choose targeted messages related to those goals, and set their scheduling to fit with key points in their everyday lives. Any of the default stored messages can be edited by the midwife to provide the client with prompts and reminders that are relevant to the individual, for example, reminders about exercise classes that happen in the client's locality or referring to specific foods that the client habitually chooses or wants to select as a replacement. Similarly, if the client and midwife together want to create a completely new message, they can do so. Regular follow-up consultations will be offered to allow goals and messages to be altered according to women's changing needs. Timing of messages is currently defined by selecting days of the week for delivery and an hour between 6 am and $10 \mathrm{pm}$.

Technically, the platform is written in php with a mySQL database running on a Windows-based server hosted by the authors' university IT services. An hourly scheduled task runs to identify what messages need sending. The messages are delivered by using a third party SMS service provider.

3.7. Focus Group Two. Women and midwives were provided with a demonstration of the proposed initial and second consultations between midwife and service user. They were also shown the booklet of messages which had been developed based on their previous suggestions. In the focus groups which followed, they were asked for their opinions of the service as a whole and of the each aspect, such as the pattern of message delivery and the content of the messages. Results emerging from the second focus group, which was aimed to explore women's and midwives opinions about the developed SMS service, are presented in Table 3 and described below 
TABLE 2: Examples of text messages.

\begin{tabular}{|c|c|c|}
\hline & & Text messages* \\
\hline \multirow{3}{*}{ Generic list } & & Exercise in pregnancy is good for you and for your baby \\
\hline & & $\begin{array}{l}\text { The more weight you put on in pregnancy, the more you'll need to } \\
\text { lose afterwards }\end{array}$ \\
\hline & & Eat for you, not for two \\
\hline \multirow{11}{*}{ Goal related list } & Motivation & It's easy to use the stairs instead of a lift-little changes all add up \\
\hline & 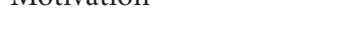 & Everyday that you exercise makes a different to you and your baby \\
\hline & & Walk to school to collect the kids this afternoon \\
\hline & Specific planning & Remember aquanatal at [TIME] ${ }^{*}$ \\
\hline & & At dinner time fill half your plate with vegetables \\
\hline & \multirow{3}{*}{ Overcoming barriers } & $\begin{array}{l}\text { If you're feeling tired, then remember that exercise can give you a } \\
\text { real energy boost }\end{array}$ \\
\hline & & $\begin{array}{l}\text { If you are feeling tired, then remember that exercise in the daytime } \\
\text { will help you to sleep at night }\end{array}$ \\
\hline & & $\begin{array}{l}\text { If you fancy a [chocolate bar }{ }^{*} \text { then try a healthier option } \\
{\text { [BANANA }]^{*} \text { instead }}^{\text {BANA }}\end{array}$ \\
\hline & \multirow{3}{*}{ Prompting self-monitoring } & If you feel hungry, then fill up with fruit and wholemeal bread \\
\hline & & $\begin{array}{l}\text { Write a diary of your walks and stair-use this week so you can see } \\
\text { how you're doing }\end{array}$ \\
\hline & & $\begin{array}{l}\text { Write a diary of your food choices this week so you can see how } \\
\text { you're doing }\end{array}$ \\
\hline
\end{tabular}

* The text messages are editable and could be altered according to women's changing needs throughout the pregnancy.

under three categories including "The service," "Content of the text messages" and "Message delivery pattern."

3.8. The Service. Participants were unanimous in their positive appraisal of the text messaging service. They commented the service would complement existing provision, would be informative, supportive, and motivational for obese pregnant women, could prevent weight problems escalating and reduce associated complications. They repeated previous opinions and that since weight concerns are not confined to the obese population, the service should be offered to all pregnant women; however, it was likely that motivated women would benefit most. Midwives believed that the service would be widely appreciated by the multidisciplinary team because it would support practitioners in their current efforts to promote weight management and healthy lifestyle among service users.

3.9. Content of the Text Messages. Participants were overwhelmingly positive about the database and booklet of "punchy, to the point" (Jackie, MW) messages which had been developed. Participants identified a number of messages they felt were particularly good, with positive elements being their wide potential appeal, motivational tone, useful information, practical application, and support for healthy choices, forward planning, and overcoming barriers. Some messages received mixed reviews, including those considered to be "dictatorial," which used words like "should," or which might create guilt; however, participants also observed that perceptions were subjective and that being able to choose for themselves meant women would select only those messages they considered positive and helpful. Suggestions for developing the database included facilitating forward planning beyond today (e.g., including references to diet and exercise choices tomorrow or next week) and mentioning loved ones (e.g., suggesting a woman might take a walk with her partner or friend), which would reinforce both exercise and its social benefits.

3.10. Message Delivery Pattern. Participants were positive about both demonstrated midwife-service user consultations at the initial stage of pregnancy prior to sending text messages. They felt that the initial consultation occurred at about the right time in the pregnancy, after the scan, at a point when the pregnancy was more clearly "viable." They also noted that nausea has often abated by 14 weeks, meaning the woman has more control over her dietary intake, and exercise of various forms is advised as safe after 12 weeks. They suggested the second face-to-face consultation visit should have an optimal duration of 20 minutes with followup visits, ranging from 2-3 times through the pregnancy to every 2-4 weeks. This led to a discussion in which both sets of participants expressed concern about the workload impact for midwives and the ability of women to attend regular faceto-face appointments, and it was suggested that while clinic attendance could be offered, some of the later consultations (e.g., after the 2nd consultation) and tweaks to messages could be carried out over the telephone on a monthly basis. Women felt that it would help make best use of time if they 
TABLE 3: Results from the second focus group on the proposed text messaging service in support of obesity management in pregnancy.

\begin{tabular}{ll}
\hline Categories & Subcategories \\
\hline & \\
& $\begin{array}{l}\text { Supportive for both women } \\
\text { and health professional team }\end{array}$
\end{tabular}

The service

Available to all

Informative

Facilitates forward planning

Engagement and choice

Message delivery pattern

Data extracts

It's all inspirational, motivation isn't it? ... to have the extra support and help there, I think it's very good (Kate) It's nice for us to know they are accessing something and it helps us, doesn't it? It's like support for us: they are being motivated by someone else. We don't see them very much: we see them at booking, 16 and 28 weeks; they can have put loads of weight on by then (Jackie, MW)

I think that probably more people should have it than just the selected ones that get invited to the clinic. I think there should be something like that for everybody (Jenny)

I thought the one that said you're not eating for two, that was good as well, because nobody actually said that to me, and I just used to make myself bigger portions all the time because I thought I was eating for two (Jenny)

I like number 8: "every day that you eat healthily and exercise makes a difference to your baby, you can do it." It's to the point and motivational at the end. It could just kick-start you that day to make you feel like you could be a bit healthier (Kathy, MW)

I quite like those planning messages but maybe even start thinking about what you're going to have tomorrow. I know when I get into bad habits it's through lack of planning (Jackie, MW)

I thought it seemed a nice, relaxed session. She [mum] was very involved in choosing. I liked that the messages were up in front of the mum (Kathy, MW)

There was no pressure to have certain ones, or to have a lot, you could just pick a few if you wanted, or you could have loads if you wanted, it's completely up to you. Because if you felt under pressure you just wouldn't enjoy it, would you? (Sally)

I'd prefer a motivational one on a couple of days when I wasn't planning on doing anything, and a food one when I knew I was gonna be staying in that night to cook, that type of thing. So probably for me, only about 5 times a week (Rachel)

Managing time and workload implications
Maybe a telephone consultation [for later appointments], rather than coming in again ... just a quick phone call: "are you still liking the messages, do you want to change anything?" (Jane, MW) could be given the message booklet to consider and select from at home.

The participants were pleased with the level of engagement and choice enjoyed by the service user, such as being able to see the computer screen, select, personalise and create messages, and choose numbers and timing of messages.

Suggestions about frequency of messages ranged from 12 per day to 2-3 per week, with general support for 3-5 per week, based upon personal preference.

\section{Discussion and Implications}

To our knowledge, this is the first study that provides a detailed account of women's and midwives' views regarding the development of a mobile technology service in support of maternal obesity management. Inclusion of women and midwives as integral components of maternity services is important for researchers and for service providers in evaluating and applying novel approaches in order to improve care. The findings from this study will form the basis for pilot trials of the developed service, testing its feasibility in practice, its acceptability to service users and providers, and its effectiveness in managing obesity during pregnancy.

Results from this localised study suggest that both women and midwives hold positive views about the potential for SMS messages as a health promotion intervention for obese pregnant women and about the developed service described above. Women were enthusiastic about the benefits they perceived for the service and future service users, and their comments suggest that women may indeed find SMS messages to encourage healthy lifestyles during pregnancy an acceptable and useful addition to the existing service. This is in keeping with Heron and Smyth's review [18], which reported that, when asked for their opinions, mobile technology service users were happy with mobile health promotion interventions. Heron and Smyth [18] identified, 
for example, that mobile technologies allowed service users to access health services when convenient and outside standard appointment times; this is supported by the women in this study, who appreciated the potential for support and advice between meetings with their midwife. In line with Cole-Lewis and Kershaw's systematic review [30], women in our study confirmed that text messaging is a potentially powerful tool for health behaviour change as it is widely available, instant, and inexpensive.

Midwives were quicker to identify potential limitations and risks associated with the proposed service and their input was extremely useful in designing a feasible service. In particular, midwives raised concerns about the possibility of causing stress, guilt, and pressure on women. These concerns are in line with their education and preparation for practice and their professional code of conduct [46], which emphasises professional accountability and safeguarding of clients. These are very important and practical points, attention to which helps optimise acceptability, participation in and compliance with healthy behaviour change interventions. Midwives' increased enthusiasm at the second data collection stage suggests that the team were successful in addressing initial anxieties. Suggestions from participating midwives and women have been used to make additional alterations to the service prior to trial, especially ideas for telephone consultations and developing messages promoting the social benefits of exercise.

The key benefits of SMS messages, according to this study, appear to lie in their ability to facilitate continuous help and motivation for pregnant women. Support and motivation have been shown to be vital elements of health promotion interventions and were strong explanatory themes for obesity, diet, and physical activity among these participants [37]. Oteng-Ntim et al. [36] identified client motivation and readiness to change as barriers to the effectiveness of service providers' efforts to promote healthy lifestyles for pregnant women. Healthy lifestyle interventions in pregnancy based on information and advice alone have shown limited effectiveness, especially with overweight women $[47,48]$. Women in the present study felt receiving SMS messages would help motivate them to stick with agreed healthy eating and exercise plans. Messages with an explicitly motivational, positive, informative content, and those which facilitated planning were particularly well evaluated in the second round of focus groups. The literature emphasises the importance of developing healthy lifestyle promotion interventions based upon models of behaviour change. As suggested by our study findings, text messages could be an ideal tool to reinforce behaviour change through involving women in decision-making, facilitating communication and promoting self-monitoring [30].

Women in this study felt at times isolated and expressed a wish for more support from peers and professionals. Social support is considered one of the key influences upon and motivators for physical activity and healthy lifestyle changes and may have particular importance for women $[49,50]$. SMS messages are designed to provide information and motivation to support healthy lifestyle changes. Women also believed SMS messages and other mobile technology interventions, such as local chat rooms, would act as a direct source of immediate support, fill the support gap between appointments with midwives, and enhance opportunities for further social contact with and mutual support from other pregnant women.

4.1. Limitations. Findings from the study are limited by the range of professionals from whom feedback was obtained since not just midwives but a variety of practitioners, including dietitians and obstetricians, are involved in the care of obese pregnant women. A dietitian team member was actively engaged in developing the service but dietitians were not sought as research participants; obstetricians were approached but none were available to participate at this stage. Midwives believed that others in the multidisciplinary team would evaluate the service positively; however, it is not possible to conclude with any confidence that this would be the case. A broader evaluation of what has been developed will be conducted with service users and a full range of relevant health professionals when the service is piloted.

The lack of representativeness of small qualitative studies may be considered as a limitation; however, these studies (including ours) are fit for their main purpose to provide in-depth information and constructs in an area with scarce available data. Perceptions and opinions of this small group of participants from Doncaster, UK, may not reflect those of midwives and service users elsewhere; however, evidence from previous research suggests these are not isolated findings. It is arguable that women interviewed here may not have been representative of other pregnant women in this locality either, despite efforts to engage as broad a spectrum as possible by inviting all eligible service users presenting over a three-month recruitment period. Lack of specific information on the socioeconomic status of the participants is another limitation of this study; however, these factors are important and will be considered in our next larger quantitative stages of the study to minimise the risk implications of skewing the findings. It is likely that participants were an unusually motivated group whose views may not reflect those of nonresponders; however, midwives' perspectives and experiences were based on a more mixed client group and presenting the two alongside one another raised a number of issues for discussion.

Participants were interviewed once before and once after service development, and it could be argued that more focus groups with these and additional participants would have increased the likelihood of producing more comprehensive and thorough findings. Nonetheless, the purpose of this small qualitative study was to identify essential elements for design of such a service for further investigation, which the team consider was achieved. The proposed service will first be trialled locally for feasibility, acceptability, and effectiveness, followed, if successful, by multisite trials which will establish the applicability of the findings and resulting intervention for a larger sample of pregnant women in this and other geographical locations. 


\section{Conclusion}

The use of text messaging in support of maternal obesity services was positively appraised by women and midwives for its potential benefits of being informative and motivational. Both groups' comments informed the development of a provisional text messaging service. Research is now required to take the evidence from this and other relevant studies to trial and evaluate this midwife-delivered SMS service in practice.

\section{Conflict of Interests}

The authors declare that they have no conflicts of interest.

\section{Authors' Contributions}

Soltani led the design of the proposal, obtained funding and ethical approval, and coordinated the development of the project. She helped with the analysis of the data, and writing the draft paper, finalised and submitted the paper. Furness collected and analysed data, put the first draft together, and helped with revisions. McSeveny collected and analysed data and helped revise the manuscript. Arden participated in study design, data analysis, and helped revise the manuscript. Garland participated in study design, participant recruitment, data analysis, and manuscript revision. Sustar contributed to the service design and commented on the manuscript. Dearen participated in study design and coordination and contributed to data analysis. All authors read and approved the final manuscript.

\section{Acknowledgments}

The authors would like to express their sincere thanks to women and midwives who took part in this study, to Naomi Watkins as a maternity service user group representative, and to Sally Atkinson, Dr. Fazilat Rahman, Lindsey Reece, and Alison Williams for their contribution to the initial stages of project development. They are also most grateful to Professor Simeon Yates for mentoring the project and to Engineering and Physical Sciences Research Council (EPSRC), Engineering for Life (EFL) and South Yorkshire Collaboration for Leadership in Applied Health Research and Care (CLAHRCSY) (Obesity and Telehealth and Care Technologies (TACT) themes) for funding this project. NIHR CLAHRC for South Yorkshire acknowledges funding from the National Institute of Health Research. The views and opinions expressed are those of the authors, and not necessarily those of the NHS, the NIHR, or the Department of Health. CLAHRC SY would also like to acknowledge the participation and resources of the partner organisations. Further details can be found at http://www.clahrc-sy.nihr.ac.uk. Engineering and Physical Sciences Research Council (EPSRC) Engineering for Life (EFL) and South Yorkshire Collaboration for Leadership in Applied Health Research and Care (CLAHRC-SY) (Obesity, User Centred Healthcare Design (UCHD) and Telehealth and Care Technologies (TACT) themes) have funded this feasibility project.

\section{References}

[1] World Health Organisation (WHO), Global Strategy of Diet, Physical Activity and Health (Obesity and Overweight), London, 2003, http://www.who.int/hpr/NPH/docs/gs_obesity.pdf.

[2] K. McPherson, T. Marsh, and M. Brown, "Modelling future trends in obesity and the impact on health," Report for Foresight, Government Office of the Chief Scientist, London, UK, 2007.

[3] M. G. Kanagalingam, N. G. Forouhi, I. A. Greer, and N. Sattar, "Changes in booking body mass index over a decade: retrospective analysis from a Glasgow Maternity Hospital," BJOG, vol. 112, no. 10, pp. 1431-1433, 2005.

[4] Confidential enquiries into Maternal and Child Health (CEMACH), Saving mothers' lives: reviewing maternal deaths to make motherhood safer. The seventh report of the confidential enquiries into maternal deaths in the United Kingdom, London, 2007.

[5] F. Galtier-Dereure, C. Boegner, and J. Bringer, "Obesity and pregnancy: complications and cost," American Journal of Clinical Nutrition, vol. 71, no. 5, pp. 1242S-1285S, 2000.

[6] N. J. Sebire, M. Jolly, J. P. Harris et al., "Maternal obesity and pregnancy outcome: a study of 287213 pregnancies in London," International Journal of Obesity, vol. 25, no. 8, pp. 1175-1182, 2001.

[7] M. L. Watkins, S. A. Rasmussen, M. A. Honein, L. D. Botto, and C. A. Moore, "Maternal obesity and risk for birth defects," Pediatrics, vol. 111, no. 5, part 2, pp. 1152-1158, 2003.

[8] J. L. Weiss, F. D. Malone, D. Emig et al., "Obesity, obstetric complications and cesarean delivery rate-a populationbased screening study," American Journal of Obstetrics and Gynecology, vol. 190, no. 4, pp. 1091-1097, 2004.

[9] H. Soltani and R. B. Fraser, "A longitudinal study of maternal anthropometric changes in normal weight, overweight and obese women during pregnancy and postpartum," British Journal of Nutrition, vol. 84, no. 1, pp. 95-101, 2000.

[10] E. Oken, E. M. Taveras, K. P. Kleinman, J. W. Rich-Edwards, and M. W. Gillman, "Gestational weight gain and child adiposity at age 3 years," American Journal of Obstetrics and Gynecology, vol. 196, no. 4, pp. 322.e1-322.e8, 2007.

[11] N. Heslehurst, R. Lang, J. Rankin, J. R. Wilkinson, and C. D. Summerbell, "Obesity in pregnancy: a study of the impact of maternal obesity on NHS maternity services," BJOG, vol. 114, no. 3, pp. 334-342, 2007.

[12] M. Blomberg, "Maternal and neonatal outcomes among obese women with weight gain below the new institute of medicine recommendations," Obstetrics \& Gynecology, vol. 117, no. 5, pp. 1065-1070, 2011.

[13] Institute of Medicine (IOM), "Weight gain during pregnancy: re-examining the guidelines," IOM, Washington, DC, USA, 2009, http://www.iom.edu/CMS/3788/48191/68004.aspx.

[14] F. Campbell, J. Messina, M. Johnson, L. Guillaume, J. Madan, and E. Goyder, Systematic Review of Dietary and/or Physical Activity Interventions for Weight Management in Pregnancy, SCHARR Public Health Collaborating Centre, Sheffield, UK, 2010.

[15] J. M. Dodd, R. M. Grivell, C. A. Crowther, and J. S. Robinson, "Antenatal interventions for overweight or obese pregnant women: a systematic review of randomised trials," BJOG, vol. 117, no. 11, pp. 1316-1326, 2010.

[16] National Institute for Health and Clinical Excellence (NICE), "Dietary interventions and physical activity interventions for weight management before, during and after pregnancy," NICE, London, 2010, http://guidance.nice.org.uk/PH27. 
[17] D. B. Sarwer, K. C. Allison, L. M. Gibbons, J. T. Markowitz, and D. B. Nelson, "Pregnancy and obesity: a review and agenda for future research," Journal of Women's Health, vol. 15, no. 6, pp. 720-733, 2006.

[18] K. E. Heron and J. M. Smyth, "Ecological momentary interventions: incorporating mobile technology into psychosocial and health behaviour treatments," British Journal of Health Psychology, vol. 15, no. 1, pp. 1-39, 2010.

[19] WHO, "mHealth: new horizons for health through mobile technologies: second global survey on eHealth," London, 2011, http://www.who.int/goe/publications/goe_mhealth_web.pdf.

[20] W. Stewart Agras, C. Barr Taylor, D. E. Feldman, M. Losch, and K. F. Burnett, "Developing computer-assisted therapy for the treatment of obesity," Behavior Therapy, vol. 21, no. 1, pp. 99-109, 1990.

[21] K. F. Burnett, C. B. Taylor, and W. S. Agras, "Ambulatory computer-assisted therapy for obesity: a new frontier for behavior therapy," Journal of Consulting and Clinical Psychology, vol. 53, no. 5, pp. 698-703, 1985.

[22] N. S. Joo and B. T. Kim, "Mobile phone short message service messaging for behaviour modification in a community-based weight control programme in Korea," Journal of Telemedicine and Telecare, vol. 13, no. 8, pp. 416-420, 2007.

[23] K. Patrick, F. Raab, M. A. Adams et al., "A text message-based intervention for weight loss: randomized controlled trial," Journal of Medical Internet Research, vol. 11, no. 1, article e1, 2009.

[24] J. Gold, C. J. Aitken, H. G. Dixon et al., "A randomised controlled trial using mobile advertising to promote safer sex and sun safety to young people," Health Education Research, vol. 26, no. 5, pp. 782-794, 2011.

[25] I. Juzang, T. Fortune, S. Black, E. Wright, and S. Bull, "A pilot programme using mobile phones for HIV prevention," Journal of Telemedicine and Telecare, vol. 17, no. 3, pp. 150-153, 2011.

[26] M. S. C. Lim, J. S. Hocking, C. K. Aitken et al., "Impact of text and email messaging on the sexual health of young people: a randomised controlled trial," Journal of Epidemiology and Community Health, vol. 66, no. 1, pp. 69-74s, 2011.

[27] S. I. Kim and H. S. Kim, "Effectiveness of mobile and internet intervention in patients with obese type 2 diabetes," International Journal of Medical Informatics, vol. 77, no. 6, pp. 399-404, 2008.

[28] I. Haapala, N. C. Barengo, S. Biggs, L. Surakka, and P. Manninen, "Weight loss by mobile phone: a 1-year effectiveness study," Public Health Nutrition, vol. 12, no. 12, pp. 2382-2391, 2009.

[29] R. Hurling, M. Catt, M. De Boni et al., "Using internet and mobile phone technology to deliver an automated physical activity program: randomized controlled trial," Journal of Medical Internet Research, vol. 9, no. 2, p. e7, 2007.

[30] H. Cole-Lewis and T. Kershaw, "Text messaging as a tool for behavior change in disease prevention and management," Epidemiologic Reviews, vol. 32, no. 1, pp. 56-69, 2010.

[31] G. Rao, L. E. Burke, B. J. Spring et al., "New and emerging weight management strategies for busy ambulatory settings: a scientific statement from the american heart association," Circulation, vol. 124, pp. 1182-1203, 2011.

[32] J. Wei, I. Hollin, and S. Kachnowski, "A review of the use of mobile phone text messaging in clinical and healthy behaviour interventions," Journal of Telemedicine and Telecare, vol. 17, no. 1, pp. 41-48, 2011.
[33] S. Krishna and S. Austin Boren, "Diabetes self-management care via cell phone: a systematic review," Journal of Diabetes Science and Technology, vol. 2, no. 3, pp. 509-517, 2008.

[34] C. Free, R. Knight, S. Robertson et al., "Smoking cessation support delivered via mobile phone text messaging (txt2stop): a single-blind, randomised trial," The Lancet, vol. 378, no. 9785, pp. 49-55, 2011.

[35] K. E. Preston, T. A. Walhart, and A. L. O’Sullivan, "Prompting healthy behavior via text messaging in adolescents and young adults," American Journal of Men's Health, vol. 5, no. 3, pp. 247-252, 2011.

[36] E. Oteng-Ntim, H. Pheasant, N. Khazaezadeh et al., "Developing a community-based maternal obesity intervention: a qualitative study of service providers' views," BJOG, vol. 117, no. 13, pp. 1651-1655, 2010.

[37] P. Furness, K. McSeveny, M. Arden, C. Garland, A. Dearden, and H. Soltani, "Maternal Obesity Support Services: a qualitative study of the perspectives of women and health care providers," BMC Pregnancy \& Childbirth, vol. 11, article 69, 2011, http://www.biomedcentral.com/1471-2393/11/69.

[38] The Association of Public Health Observatories, 2009, http://www.apho.org.uk/.

[39] D. W. Stewart, P. N. Shamdesani, and D. W. Rook, Focus Groups Theory and Practice, Sage, Thousand Oaks, Calif, USA, 2nd edition, 2007.

[40] R. A. Krueger and M. A. Casey, Focus Groups: A Practical Guide for Applied Research, Sage, Thousand Oaks, Calif, USA, 2009.

[41] A. Bryman, Social Research Methods, Oxford University Press, Oxford, UK, 2001.

[42] B. L. Berg, Qualitative Research Methods for the Social Sciences, Pearson Press, Boston, Mass, USA, 5th edition, 2004.

[43] S. Michie, C. Abraham, C. Whittington, J. McAteer, and S. Gupta, "Effective techniques in healthy eating and physical activity interventions: a meta-regression," Health Psychology, vol. 28 , no. 6, pp. 690-701, 2009.

[44] K. R. Evenson, M. K. Moos, K. Carrier, and A. M. SiegaRiz, "Perceived barriers to physical activity among pregnant women," Maternal and Child Health Journal, vol. 13, no. 3, pp. 364-375, 2009.

[45] D. Schuler and A. Namioka, Participatory Design: Principles and Practices, Erlbaum, Hillsdale, NJ, USA, 1993.

[46] Nursing and Midwifery Council, "The code: standards of conduct, performance and ethics for nurses and midwives," London, UK, 2010, https://www.nmc-uk.org/.

[47] T. Østbye, K. M. Krause, C. A. Lovelady et al., "Active mothers postpartum: a randomized controlled weight-loss intervention trial," American Journal of Preventive Medicine, vol. 37, no. 3, pp. 173-180, 2009.

[48] B. A. Polley, R. R. Wing, and C. J. Sims, "Randomized controlled trial to prevent excessive weight gain in pregnant women," International Journal of Obesity, vol. 26, no. 11, pp. 1494-1502, 2002.

[49] A. A. Eyler, E. Baker, L. Cromer, A. C. King, R. C. Brownson, and R. J. Donatelle, "Physical activity and minority women: a qualitative study," Health Education and Behavior, vol. 25, no. 5, pp. 640-652, 1998.

[50] C. Keller, J. Allan, and M. B. Tinkle, "Stages of change, processes of change, and social support for exercise and weight gain in postpartum women," Journal of Obstetric, Gynecologic, and Neonatal Nursing, vol. 35, no. 2, pp. 232-240, 2006. 


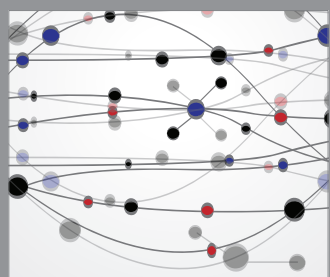

The Scientific World Journal
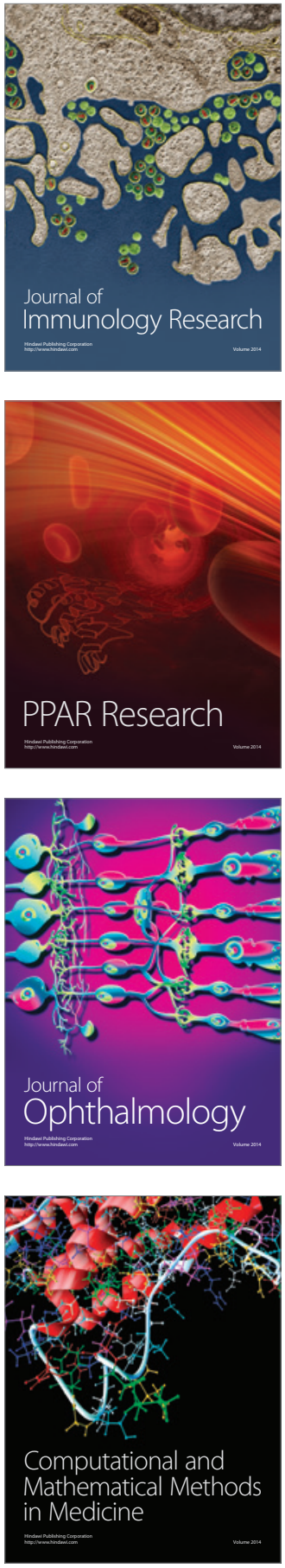

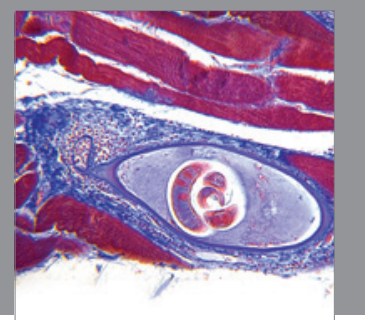

Gastroenterology

Research and Practice
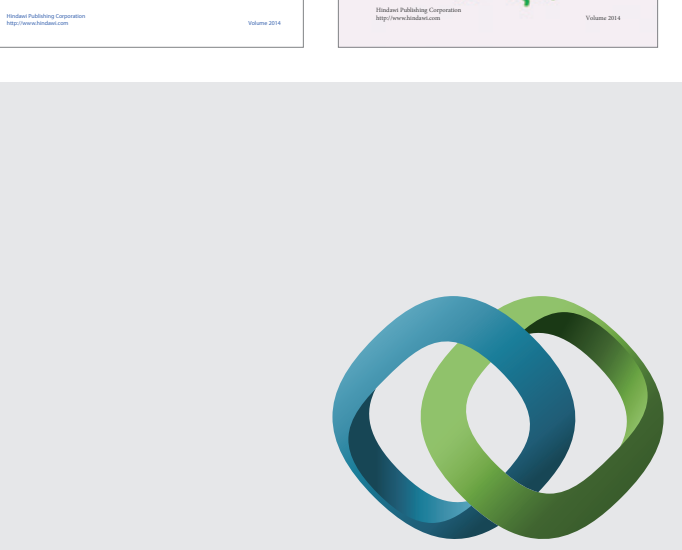

\section{Hindawi}

Submit your manuscripts at

http://www.hindawi.com
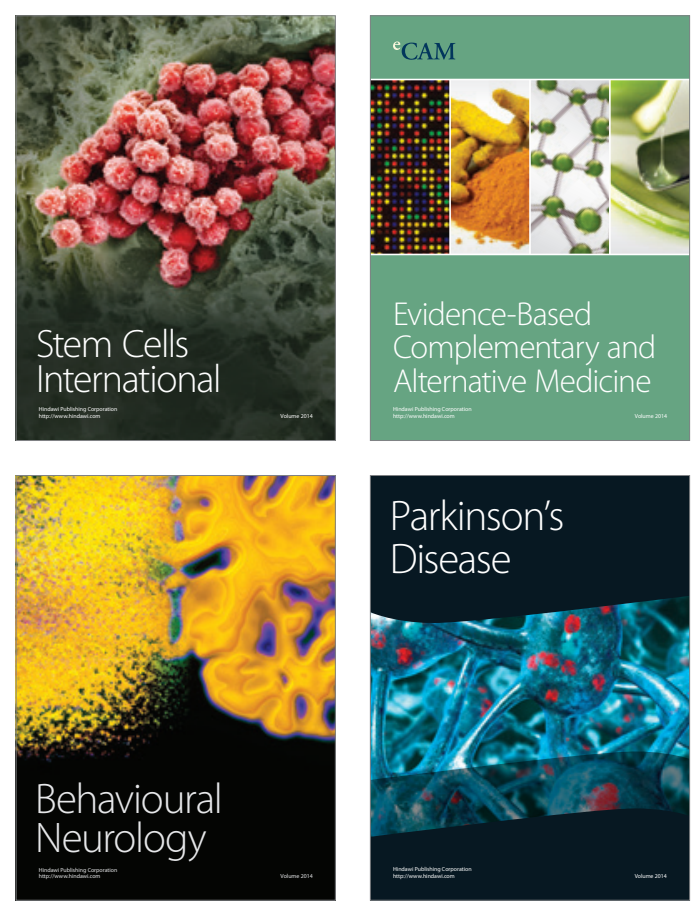

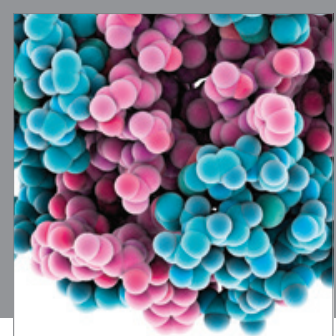

Journal of
Diabetes Research

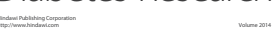

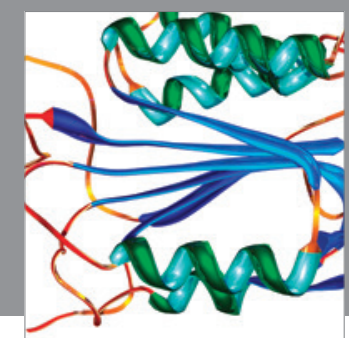

Disease Markers
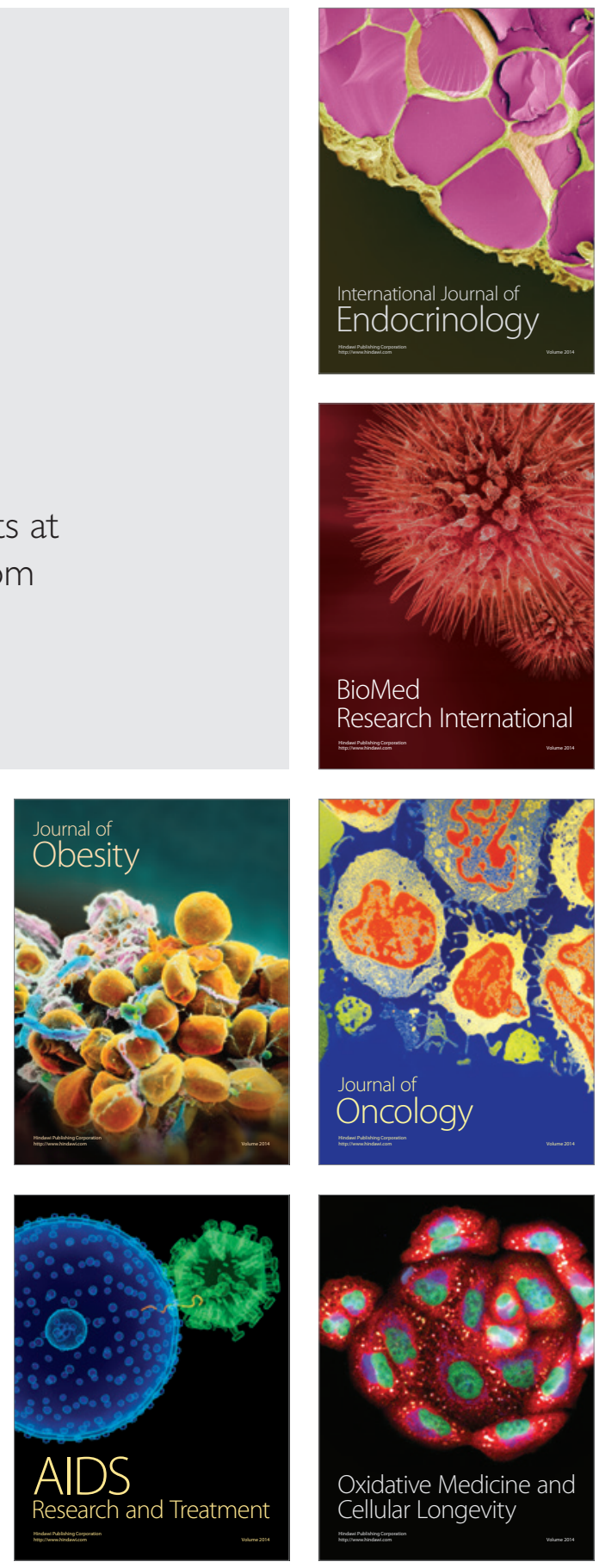